\title{
Size controlled protein nanoemulsions for active targeting of folate receptor positive cells
}

\author{
Ana Loureiro $^{\mathrm{a}, \mathrm{b}}$, Eugénia Nogueira ${ }^{\mathrm{a}, \mathrm{b}}$, Nuno G. Azoia $^{\mathrm{a}}$, Marisa P. Sárria ${ }^{\mathrm{a}, \mathrm{b}}$, Ana S. Abreu $^{\mathrm{a}, 1}$, \\ Ulyana Shimanovich $^{\mathrm{c}}$, Alexandra Rollett ${ }^{\mathrm{d}}$, Johan Härmark ${ }^{\mathrm{e}}$, Hans Hebert ${ }^{\mathrm{e}}$, \\ Georg Guebitz $^{\mathrm{d}, \mathrm{f}}$, Gonçalo J.L. Bernardes ${ }^{\mathrm{c}, \mathrm{g}}$, Ana Preto ${ }^{\mathrm{b}}$, Andreia C. Gomes ${ }^{\mathrm{b}}$, \\ Artur Cavaco-Paulo ${ }^{\mathrm{a}, *}$ \\ a CEB - Centre of Biological Engineering, University of Minho, Campus of Gualtar, 4710-057 Braga, Portugal \\ ${ }^{\mathrm{b}}$ CBMA (Centre of Molecular and Environmental Biology), Department of Biology, University of Minho, Campus of Gualtar, 4710-057 Braga, Portugal \\ ${ }^{\mathrm{c}}$ Department of Chemistry, University of Cambridge, Lensfield Road, Cambridge CB2 1EW, United Kingdom \\ d University of Natural Resources and Life Sciences, Institute for Environmental Biotechnology, IFA Tulln, Konrad Lorenz Straße 20, 3430 Tulln, Vienna, \\ Austria \\ e Department of Biosciences and Nutrition, The Royal Institute of Technology, School of Technology and Health, Karolinska Institutet, Stockholm, Sweden \\ ${ }^{\mathrm{f}}$ Austrian Centre of Industrial Biotechnology, Petersgasse 14, $8010 \mathrm{Graz}$, Austria \\ ${ }^{\mathrm{g}}$ Instituto de Medicina Molecular, Faculdade de Medicina da Universidade de Lisboa, Av. Prof. Egas Moniz, 1649-028 Lisboa, Portugal
}

\section{A R T I C L E I N F O}

\section{Article history:}

Received 18 March 2015

Received in revised form 2 June 2015

Accepted 25 June 2015

Available online 17 July 2015

\section{Keywords:}

Protein-based nanoemulsions

High pressure homogenization

PEGylated surfactant

Folic acid

Active targeting

\begin{abstract}
A B S T R A C T
Bovine serum albumin (BSA) nanoemulsions were produced by high pressure homogenization with a tri-block copolymer (Poloxamer 407), which presents a central hydrophobic chain of polyoxypropylene (PPO) and two identical lateral hydrophilic chains of polyethylene glycol (PEG). We observed a linear correlation between tri-block copolymer concentration and size - the use of $5 \mathrm{mg} / \mathrm{mL}$ of Poloxamer 407 yields nanoemulsions smaller than $100 \mathrm{~nm}$. Molecular dynamics and fluorescent tagging of the tri-block copolymer highlight their mechanistic role on the size of emulsions. This novel method enables the fabrication of highly stable albumin emulsions in the nano-size range, highly desirable for controlled drug delivery. Folic Acid (FA)-tagged protein nanoemulsions were shown to promote specific folate receptor (FR)-mediated targeting in FR positive cells. The novel strategy presented here enables the construction of size controlled, functionalized protein-based nanoemulsions with excellent characteristics for active targeting in cancer therapy.
\end{abstract}

(C) 2015 Elsevier B.V. All rights reserved.

\section{Introduction}

Particle size is a feature of particular importance for intravenous therapeutic applications. Nanoparticles intended for systemic circulation should be large enough to prevent their rapid leakage into blood capillaries but small enough to escape capture by macrophages in the reticuloendothelial system, such as in the liver and spleen $[1,2]$. Nanoparticles for drug delivery smaller than $100 \mathrm{~nm}$ can be intravenously administered and are taken up more efficiently by cells [3].

\footnotetext{
* Corresponding author.

E-mail address: artur@deb.uminho.pt (A. Cavaco-Paulo).

1 Present address: Institute of Polymers and Composites (IPC) and Institute of Nanostructures, Nanomodelling and Nanofabrication (I3N), University of Minho, Campus de Azurém, 4800-058 Guimarães, Portugal.
}

Albumin is widely used to prepare protein nanoparticles, which can be easily functionalized chemically [4]. Functionalized nanoparticles can be utilized for targeted drug delivery, improving cellular uptake and ameliorating undesired toxic side effects associated with conventional chemotherapeutic regimens $[3,5]$.

The state of the art on the production and mechanism of formation of protein-based capsules was recently reviewed by our group [6]. The production of albumin-based nanoparticles can be achieved using specialized nanotechnology techniques like desolvation, emulsification, thermal gelation, and more recently through nano-spray drying, nab-technology and self-assembly [4,6-8]. Suslick and Grinstaff, were pioneers in developing a methodology using high-intensity ultrasound, which is a high-energy emulsification method, to produce aqueous suspensions of proteinaceous microcapsules [9]. It was demonstrated that high shear forces applied to biphasic water/hydrophobic solvent systems can induce conformation changes in proteins which tend to migrate to the water/solvent 
interface, stabilizing the microcapsules $[6,10]$. In a previous study, our group demonstrated that the use of a large globular protein, BSA, with clear distinct hydrophilic and hydrophobic areas, $n$ dodecane (as an organic solvent) and a ratio of $95 \%$ of aqueous phase $/ 5 \%$ of $n$-dodecane subjected to high-intensity ultrasound, resulted in small and stable microspheres. However, the particles produced using this method never presented size smaller than $250 \mathrm{~nm}[10]$.

Here, we describe a novel method based on high pressure homogenization (also a high-energy emulsification method) rather than using high-intensity ultrasound, of a biphasic system (aqueous phase and vegetable oil) to produce stable protein nanoparticles of small, defined and controllable size. Taking into account the production method, where an aqueous solution and oil are emulsified by high pressure homogenization, we denominated these nanoparticles as nanoemulsions. The addition of a PEGylated surfactant (Poloxamer 407) regulates the particle size while the chemical functionalization of albumin with FA confers specificity toward FR positive cells, thus achieving active targeting.

\section{Material and methods}

\subsection{Nanoemulsion preparation}

The preparation of nanoemulsions was achieved using a high pressure homogenizer (APV-2000, Denmark). BSA (Sigma-Aldrich, USA) previously dissolved in phosphate buffered saline (PBS, salt concentration $150 \mathrm{mM}$ ) was emulsified with an organic solvent (vegetable oil) by subjecting the mixture to varying number of homogenization cycles at high pressure. Different concentrations of BSA ( $1 ; 5 ; 10$ and $50 \mathrm{mg} / \mathrm{mL}$ ), of Poloxamer 407 (Sigma-Aldrich, USA) and different ratios of protein solution/vegetable oil (95/5; 99.5/0.5) were tested in order to determine how these factors influence the properties of the resulting particles. PBS concentration was maintained constant throughout the study to avoid the influence of salt concentration in the production optimization.

A fluorescent agent was introduced in the aqueous phase by using Fluorescein isothiocyanate (FITC) labelled-BSA (Sigma-Aldrich, USA) at an initial formulation of a 1:20 ratio $(\mathrm{m} / \mathrm{m})$. Previously prepared BSA-FA conjugate solution was added at $1: 100$ ratio $(\mathrm{m} / \mathrm{m})$ to the aqueous phase to obtain nanoemulsions with FA (the targeting agent) on their surface.

\subsection{Conjugation of FA with BSA}

In brief, FA (Sigma-Aldrich, USA) was dissolved in PBS, pH 7.4, and 'activated' with 5-fold excess of $\mathrm{N}$-(3-dimethylaminopropyl)$N^{\prime}$-ethylcarbodiimide hydrochloride (Sigma-Aldrich, USA) and a 1 -fold excess of $N$-hydroxysulfosuccinimide (Sigma-Aldrich, USA) for $2 \mathrm{~h}$ at room temperature. To this activated FA was then added $10 \mathrm{mg} / \mathrm{mL}$ of BSA and left to react for 8-10 h, using a 75:1 FA to BSA moles ratio. The excess FA and other reactants were removed from the conjugated protein by dialyzing against PBS for 8 days. After dialysis, quantification of FA linked to BSA was determined by spectroscopic measurements at the maximum wavelength of $350 \mathrm{~nm}$. Using a calibration curve of different concentrations of FA, the concentration of FA linked to BSA was determined. The quantitation of BSA was performed with Bio-Rad protein assay (Bio-Rad laboratories, $\mathrm{GmbH}$ ) based on the shift of absorbance maximum for an acidic solution of Coomassie Brilliant Blue G-2SO at $595 \mathrm{~nm}$ when binding to protein occurred. Therefore, it was found that $1.625 \mathrm{mg} / \mathrm{mL}$ of FA was linked to $7 \mathrm{mg} / \mathrm{mL}$ of BSA, which corresponds to 35 moles of FA per 1 mole of BSA.

\subsection{Determination of size, zeta-potential and long-time stability}

The nanoemulsions were analyzed for their size distribution and their zeta-potential ( $\zeta$-potential), at pH 7.4 (PBS buffer) and at $25^{\circ} \mathrm{C}$, using dynamic light scattering in a Malvern zetasizer NS, by photon correlation spectroscopy (PCS) and by electrophoretic laser Doppler anemometry, respectively. The protein concentration was kept constant at $10 \mathrm{mg} / \mathrm{mL}$. The values for viscosity and refractive index were taken as $0.890 \mathrm{cP}$ and 1.330 , respectively. Each sample was measured in triplicate and results are presented as mean value \pm standard deviation.

Nanoemulsions, in suspension, were stored at $4{ }^{\circ} \mathrm{C}$ for a period of 20 weeks. After predetermined storage times, the stability parameters, particles size, polydispersity and zeta-potential, were determined as described above.

The nanoemulsion's stability was also evaluated in biological medium through the incubation in PBS buffer containing $10 \%$ of fetal bovine serum (FBS) at $37^{\circ} \mathrm{C}$ for $24 \mathrm{~h}$.

\subsection{Determination of nanoemulsion formation efficiency}

The amount of BSA used in nanoemulsion production was quantified by measuring the amount of free protein with the Bradford protein assay (Bio-Rad Laboratories, USA), using BSA solutions as standards. After synthesis, the nanoparticles-containing phase was collected by centrifugation $(1000 \times g$ for $45 \mathrm{~min})$ using centricon tubes (Amicon Ultra-15, Millipore), a centrifugal filter unit containing a cellulose membrane with a molecular weight cut-off of $100 \mathrm{KDa}$. The free protein in the aqueous phase after separation was quantified and the efficiency of nanoemulsion formation was determined using the formula:

Nanoemulsion formation $(\%)=\frac{[C]_{\mathrm{i}}-[C]_{\mathrm{f}}}{[C]_{\mathrm{i}}} \times 100$

where $[C]_{\mathrm{i}}$ and $[C]_{\mathrm{f}}$ is the initial and final concentration of the protein in the aqueous solution, respectively. Each sample was assayed in triplicate.

\subsection{Determination of entrapment efficiency of different pharmacological drugs}

The hydrophilic drugs were dissolved in aqueous phase and the hydrophobic in oil phase of the initial formulation, which was posteriorly subjected to high pressure homogenization. The initial concentration of each drug was: 5 -Fluorouracil $=788 \mu \mathrm{g} / \mathrm{mL}$; doxorubicin $=50 \mu \mathrm{g} / \mathrm{mL}$; methotrexate $=688.5 \mu \mathrm{g} / \mathrm{mL}$; taxol $=2.5 \mu \mathrm{g} / \mathrm{mL}$; carbon monoxide releasing molecule-2 $($ CORM-2) $=100 \mu \mathrm{g} / \mathrm{mL}$. Calibration curves with different concentrations of each hydrophilic drug were performed by spectroscopic measurements at the maximum wavelengths (5-Fluorouracil: $265.5 \mathrm{~nm}$; doxorrubicin: $481 \mathrm{~nm}$; methotrexate: $302 \mathrm{~nm}$ ) and the respective LOD were calculated to be: 5 -Fluorouracil $=0.0446 \mu \mathrm{g} / \mathrm{mL}$; doxorubicin $=0.0362 \mu \mathrm{g} / \mathrm{mL}$; methotrexate $=0.0443 \mu \mathrm{g} / \mathrm{mL}$ according to [11]. After nanoemulsion production, a separation of phases were performed by centrifugation $(1000 \times \mathrm{g}$ for $45 \mathrm{~min})$ using centricon tubes (Amicon Ultra-15, Millipore). The free drug in the aqueous phase was quantified and the entrapment efficiency was determined using the formula:

Entrapment efficiency $(\%)=\frac{[\mathrm{drug}]_{\text {Total }}-[\mathrm{drug}]_{\text {Free }}}{[\mathrm{drug}]_{\text {Total }}} \times 100$

where $[\mathrm{drug}]_{\text {Total }}$ and $[\mathrm{drug}]_{\text {Free }}$ is the total concentration of drug added in formulation and the free concentration of drug in aqueous phase solution, respectively. 


\subsection{Morphology of nanoemulsions}

The morphology of the BSA nanoemulsions was examined by fluorescence microscopy and transmissions electron microscopy (TEM) imaging systems. The nanoemulsion solution was analyzed in a Leica DM5000B fluorescence microscope in order to determine if fluorescently labeled protein was present at the nanoparticle's surface. For TEM analyses, nanoemulsion samples were applied to glow discharged carbon-coated copper grids followed by negative staining with a solution of $1 \%(w / v)$ Uranyl acetate and then analyzed in a JEOL JEM2100F transmission electron microscope.

\subsection{Molecular dynamics simulation}

The simulations were performed with the software package GROMACS [12], using Martini force-field [13-15]. The system size was chosen according to the minimum image convention taking into account a cut-off of $1.2 \mathrm{~nm}$. The bonds lengths were constrained with LINCS [16]. Non-bonded interactions were calculated using a twin-range method, with short and long range cut-offs of $0.9-1.2 \mathrm{~nm}$, respectively. Neighbor searching was carried out up to $1.2 \mathrm{~nm}$ and updated every ten steps. A time step of integration of $5 \mathrm{fs}$ was used. A reaction field correction for the electrostatic interactions was applied using a dielectric constant of 15. Pressure control was implemented using the Berendsen barostat [17], with a reference pressure of $1 \mathrm{bar}, 3.0 \mathrm{ps}$ of relaxation time and isothermal compressibility of $3.0 \times 10^{-5} \mathrm{bar}^{-1}$. Temperature control was set using the Berendsen thermostat [17] at $300 \mathrm{~K}$. Each component of the system was included in separated heat bath, with temperatures coupling constants of $0.30 \mathrm{ps}$. Two replica simulations of $250 \mathrm{~ns}$ in length were carried out using different initial velocities taken from a Maxwell-Boltzman distribution at $300 \mathrm{~K}$. Initially the components were distributed uniformly through the simulation box and allowed to interact freely during the simulation. The simulations were extended to $250 \mathrm{~ns}$ and not more because the system had reached an equilibrium. No significant changes were observed, in both the energy and position and distribution of the particles in the system, in the last nanoseconds of the simulations.

\subsection{Particle preparation, using ultrasound methodology, for confocal observations}

In order to produce larger sized particles to facilitate confocal analysis, the bottom of a high-intensity ultrasonic horn was positioned at the interface of the protein aqueous solution and vegetable oil and activated at an amplitude of $40 \%$ at $10^{\circ} \mathrm{C}( \pm 1)$ for $3 \mathrm{~min}$. The ratio of aqueous/organic phase (\%) used were $90 / 10$, and $5 \mathrm{mg} / \mathrm{mL}$ of BSA and $5 \mathrm{mg} / \mathrm{mL}$ of Poloxamer 407 were introduced in the aqueous phase. BSA-FITC and Poloxamer 407-rhodamine B solution, previously prepared, were used for particle preparation.

\subsection{Conjugation of rhodamine B with poloxamer 407}

Poloxamer 407 coupled with rhodamine B (Sigma-Aldrich, USA) was synthesized using the Steglich esterification method [18]. Briefly, rhodamine B $(0.2 \mathrm{mM})$ preactivated with $N, N^{\prime}-$ dicyclohexylcarbodiimide (DCC) (Sigma-Aldrich, USA) (0.2 mM) was conjugated to the hydroxyl $(\mathrm{OH})$ groups of Poloxamer $(0.1 \mathrm{mM})$ in dichloromethane (DCM) $(20 \mathrm{~mL})$ including 4-(dimethylamino) pyridine (DMAP) $(0.2 \mathrm{mM})$, triethylamine $(0.1 \mathrm{~mL})$, and pyridine $(0.1 \mathrm{~mL})$ (Sigma-Aldrich, USA). The solution was stirred at room temperature for 1 day. After the reaction, the solution was filtered and the solvent evaporated under reduced pressure. The resulting light pink solid was then dissolved in PBS and the excess rhodamine $B$ and other reactants were removed from conjugated poloxamer using benzoylated dialysis tubing (Sigma-Aldrich, MWCO 2 KDa).
Dialysis was performed against PBS, pH 7.4, for 3 days. The dialysis was stopped when no rhodamine B was detected in the dialysis buffer.

\subsection{Cells and culture conditions}

Human skin fibroblasts (BJ5ta cell line) (ATCC, CRL-4001) and a subclone of HeLa cells [19] (KB cell line) (ATCC, CCL-17) were obtained from American Type Culture Collection (LGC Standards, UK).

Exponentially growing cultures were maintained in a humidified atmosphere of $5 \% \mathrm{CO}_{2}$ in air at $37^{\circ} \mathrm{C}$. All culture media and supplements were purchased from Sigma-Aldrich. Adherent cell lines (BJ5ta and KB cells) were grown in T75 flasks (TPP, Switzerland).

\begin{tabular}{lll}
\hline $\begin{array}{l}\text { Cell } \\
\text { line }\end{array}$ & Media & Supplements \\
\hline BJ5ta & 4 Parts of Dulbeccoís modified & $2 \mathrm{mM}$ L-glutamine; $4.5 \mathrm{mg} / \mathrm{mL}$ glucose; \\
& eagle's medium (DMEM) & $1.5 \mathrm{mg} / \mathrm{mL}$ sodium bicarbonate; $10 \%$ \\
& 1 Part of M199 Medium & $\begin{array}{l}(v / v) \text { of FBS; } 1 \%(v / v) \text { of } \\
\text { penicillin } / \text { streptomycin solution; }\end{array}$ \\
& & $10 \mu \mathrm{g} / \mathrm{mL}$ of hygromycin B \\
KB & RPMI-1640 Medium & $10 \%(v / v)$ FBS; $1 \%(v / v)$ \\
& & $\begin{array}{l}\text { penicillin } / \mathrm{streptomycin} \text { solution; } 2 \mathrm{mM} \\
\text { of L-glutamine; } 2 \mathrm{mg} / \mathrm{mL} \text { sodium } \\
\text { bicarbonate }\end{array}$ \\
& & \\
\hline
\end{tabular}

\subsection{Cell viability assay}

Cell viability was studied using the Promega CellTiter $96^{\circledR}$ AQueous non-radioactive cell proliferation (MTS) assay (Promega, USA). BJ5ta cells were seeded in 96-well tissue culture polystyrene plates (TPP, Switzerland) at a density of $1.1 \times 10^{4}$ cells/well and incubated overnight to promote cell adhesion. The cells were incubated with different concentrations of nanoemulsions (from 75 up to $900 \mu \mathrm{g} / \mathrm{mL}$ ) and following incubation for 24,48 and $72 \mathrm{~h}$, a MTS mixture was then added and the cells were further incubated for $4 \mathrm{~h}$ at $37^{\circ} \mathrm{C}$. After this period, the plates were placed on Spectra MAX 340PC microwell plate reader and the absorbance of the formazan product was read at $490 \mathrm{~nm}$. Cell viability was expressed as a percentage relative to the negative control (untreated control cells).

\subsection{Quantification of oxidative stress $-2^{\prime}-7^{\prime}$-dichlorofluorescein assay}

BJ5ta cells were seeded in 12-well plates (TPP, Switzerland) at a density of $1 \times 10^{5}$ cells/well and, after overnight cellular adhesion, incubated with different concentrations of nanoemulsions (from 75 up to $900 \mu \mathrm{g} / \mathrm{mL}$ ) for 12,24 and $48 \mathrm{~h}$. After each period of incubation, cells were washed twice with PBS buffer and incubated with $200 \mu \mathrm{L}$ of a $100 \mu \mathrm{M} \mathrm{DCFH}_{2}$-DA (Molecular Probes by Life Technologies, USA) solution for $30 \mathrm{~min}$ in the dark at $37^{\circ} \mathrm{C}$. Extracellular $\mathrm{DCFH}_{2}$-DA was removed by washing the cells twice with PBS buffer. Hydrogen peroxide $\left(\mathrm{H}_{2} \mathrm{O}_{2}\right)$ was then added to the positive control in this phase $(1: 5(v / v)$ ). Lysis solution (90\% DMSO solution/10\% PBS buffer $(v / v)$ ) was added and cells incubated on a shaker for $10 \mathrm{~min}$ in a dark at room temperature. The lysates were transferred in to black opaque 96-well plates and fluorescence intensity was then read using wavelengths of $485 \mathrm{~nm}$ excitation and $525 \mathrm{~nm}$ emission, at $25^{\circ} \mathrm{C}$, using a Fluoroskan Ascent FL plate reader.

\subsection{Confocal microscopy}

BSA nanoemulsions containing FITC labeled-BSA and FA-BSA conjugate at their particle's surface were prepared and their inter- 


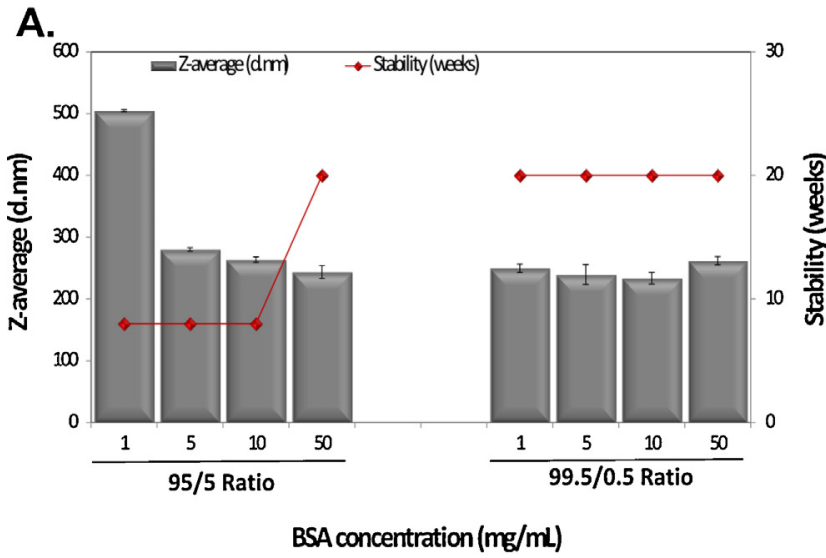

B.<smiles>CC(C)(O)CCOCC(C)(C)COCCO</smiles>

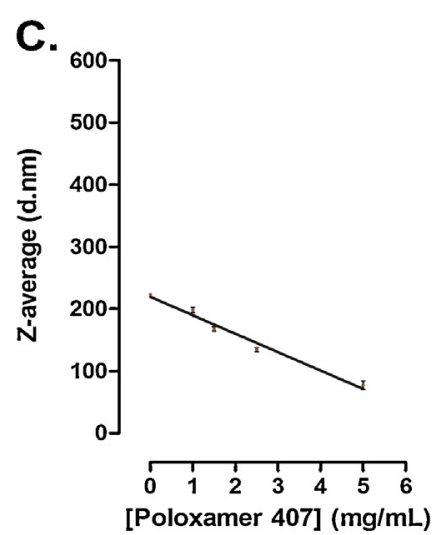

D.

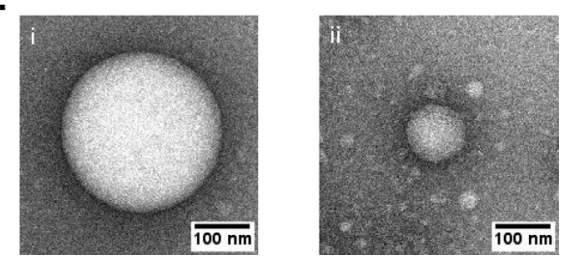

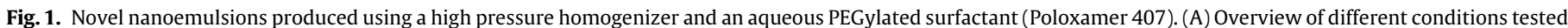

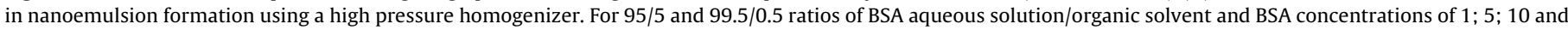

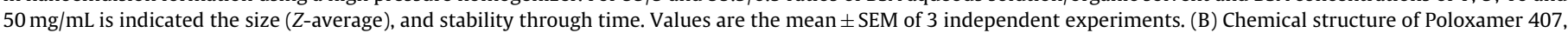

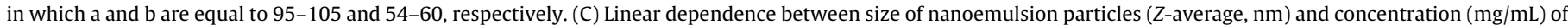

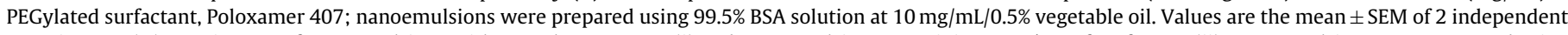

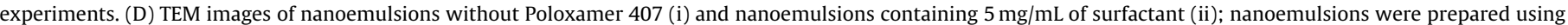
$99.5 \%$ BSA solution at $10 \mathrm{mg} / \mathrm{mL} / 0.5 \%$ vegetable oil.

nalization by cells was analyzed after separation of unbound FITC-BSA and FA-BSA using centricon tubes. The FR positive cancer cell line KB cell line was used in this study. KB cells were seeded at a density of $5 \times 10^{4}$ cells/well and incubated overnight to promote cell adhesion. Solutions of nanoemulsions with and without FA fusions were prepared in FA-free Hanks' Balanced Salt solution (HBSS medium) (Lonza, Belgium). Cells were washed twice with PBS buffer and then $300 \mu \mathrm{g} / \mathrm{mL}$ nanoemulsion suspensions were added to the monolayer, which was then incubated at $37^{\circ} \mathrm{C}$ for $2 \mathrm{~h}$. After three further washing steps with cold PBS buffer, cells were fixed with $500 \mu \mathrm{L}$ of paraformaldehyde $4 \%(v / v)$ for $30 \mathrm{~min}$ and permeabilized with Triton $0.1 \%(v / v)$ solution. After two washing steps with PBS, the fixed cells were incubated with 5 units $/ \mathrm{mL}$ of Alexa Fluor 568 Phalloidin (Molecular Probes by Life Technologies, USA). The coverslips were placed on slides coated with $2 \mu \mathrm{L}$ of Permafluor (Thermo Scientific, United Kingdom) containing $5 \mu \mathrm{g} / \mathrm{mL}$ of Hoechst (Molecular Probes by Life Technologies, USA).

Microscopic observations were performed using an inverted Zeiss confocal laser scanning microscope (CLSM; Olympus Fluoview FV1000).

BSA emulsions containing FITC labeled-BSA and rhodamine B labeled-Poloxamer 407 and prepared using the ultrasound method were also observed by confocal laser scanning microscopy.

Three dimensional models were produced with the software Imaris image analysis program.

\subsection{Cell uptake quantification}

KB cells were seeded in 6-well plates (TPP, Switzerland) at a density of $2 \times 10^{5}$ cells/well and incubated overnight to promote cell adhesion. Solutions of nanoemulsions with and without FA fusions were prepared in HBSS medium. Cells were washed twice with PBS pH 7.4 and nanoemulsion suspensions at a concentration of $300 \mu \mathrm{g} / \mathrm{ml}$ were added to the monolayer of cells and incubated at $37^{\circ} \mathrm{C}$ for $2 \mathrm{~h}$. After three further washing steps with cold PBS, cells were lysed with one solution of Tris-HCl buffer at $10 \mathrm{mM}$ and the fluorescence of these solutions was then analyzed with an Horiba Jobin Yvon Spex Fluorolog-3 spectrofluorimeter using the $\lambda_{\text {exc }}=480 \mathrm{~nm}$, scanning within a wavelength range of $490-650 \mathrm{~nm}$. Calibration curves of each solution of tested nanoemulsions were also measured.

\section{Results and discussion}

\subsection{High pressure homogenization methodology for producing stable and size controlled nanoemulsions}

For the production of functionalized nanoemulsions of a defined size, we used a high pressure homogenizer. High pressure systems are continuously operated and droplet disruption is achieved through a combination of turbulent flow and laminar flow producing shear stresses and cavitation [20]. Different emulsification steps are usually involved in preparing nanoparticles by high pressure homogenizer and, in some cases, the addition of cross-linking agents is necessary [21-25]. The strategy described here involves a single step of emulsification which allows high batch-to-batch reproducibility, ease of scale-up, simplicity, resulting in homogenously small, highly stable protein nanoemulsions. In a previous study, we demonstrated that the hydrodynamic cavitation phenomenon involved in high pressure homogenizer creates negligible amounts of radicals, when compared with ultrasound [26]. The applied pressures and the number of homogenization cycles can affect particle size and stability in the final emulsion. Stable emulsions were obtained when using a pressure of $600 \mathrm{bar}$, in the first stage of pressure, and $250 \mathrm{bar}$, in the second stage of pressure and, when applying 26 homogenization cycles. The ratio between 
Table 1

Cell viability after $72 \mathrm{~h}$ of contact using BJ5ta cells and oxidative stress induction after $48 \mathrm{~h}$ of contact with nanoemulsions. (n.d. = not determined).

\begin{tabular}{|c|c|c|}
\hline & $\begin{array}{l}\text { Concentration range } \\
\text { with viability higher } \\
\text { than } 90 \%(\mu \mathrm{g} / \mathrm{mL})\end{array}$ & $\begin{array}{l}\text { Oxidative stress levels } \\
\text { in exposed cells (DCF } \\
\text { assay) }\end{array}$ \\
\hline${ }^{\mathrm{a}}$ Nanoemulsions (ratio 95/5) & $<75$ & n.d. \\
\hline $\begin{array}{l}{ }^{a} \text { Nanoemulsions (ratio } \\
99.5 / 0.5 \text { ) }\end{array}$ & $<900$ & Similar to control cells \\
\hline $\begin{array}{l}\text { a Nanoemulsions (ratio } \\
99.5 / 0.5 \text { ) + Poloxamer } 407\end{array}$ & $<900$ & Similar to control cells \\
\hline
\end{tabular}

a Nanoemulsions were prepared using BSA solution at $10 \mathrm{mg} / \mathrm{mL}$ and oil with specified ratios and with $5 \mathrm{mg} / \mathrm{mL}$ of Poloxamer 407 in aqueous solution when indicated.

BSA solution and organic solvent may also influence the size of the resulting nanoemulsion particles, as observed when using ultrasonic procedures [10]. Two different BSA/vegetable oil ratios, $95 \% / 5 \%$ and $99.5 \% / 0.5 \%$, were tested using different BSA concentrations $(1 ; 5 ; 10$ and $50 \mathrm{mg} / \mathrm{mL})$. The size and stability of these samples over time were analyzed (Fig. 1A). Nanoemulsions prepared using high concentrations of protein ( 10 and $50 \mathrm{mg} / \mathrm{mL}$ ) were formed with high efficiency (above 90\%) and displayed smaller sizes and higher stability over time (Fig. 1A). Nanoemulsions prepared with lower vegetable oil content exhibited constant size (Fig. 1A), polydispersity and zeta-potential values (data not shown) for 20 weeks.

Cytotoxicity evaluation using immortalized human normal skin fibroblasts further supported that 99.5\% BSA solution at $10 \mathrm{mg} / \mathrm{mL} / 0.5 \%$ vegetable oil was ideal for nanoemulsion preparation. While some cytotoxicity was induced in fibroblasts exposed to nanoemulsions prepared with higher oil content, no cytotoxicity whatsoever was detected in cells contacting for at least $72 \mathrm{~h}$ with nanoemulsions prepared with a low oil content (Table 1). From this point onwards, the nanoemulsions were always prepared using $99.5 \%$ BSA solution at $10 \mathrm{mg} / \mathrm{mL} / 0.5 \%$ vegetable oil.

\subsection{Poloxamer 407 concentrations have a direct effect on nanoemulsion size}

The inclusion of hydrophilic non-ionic surfactant (Poloxamer 407) was investigated as a means to obtain homogeneously small nanoemulsions with stealthing features, required for systemic administration. Poloxamer 407 is a tri-block copolymer with a central hydrophobic chain of polyoxypropylene (PPO) and two identical lateral hydrophilic chains of polyethylene glycol (PEG) (Fig. 1B). A linear correlation was found between surfactant concentration and nanoemulsion particle size (Fig. 1C), illustrated by dynamic light scattering. TEM imaging confirmed these results and revealed spherical shaped BSA based nanoemulsions (Fig. 1D). These results are in agreement with a previous characterization using STEM imaging, reported by us [27].

The physicochemical characterization of nanoemulsions containing Poloxamer 407 showed that, in addition to the precise control of nanoemulsion particle size, the presence of the PEGylated surfactant also determines their surface characteristics. The introduction of $5 \mathrm{mg} / \mathrm{mL}$ of Poloxamer 407 into the formulation resulted in nanoemulsion particles smaller than $100 \mathrm{~nm}$ and with a zeta-potential close to zero. Even after 20 weeks of storage in PBS at $4{ }^{\circ} \mathrm{C}$, the properties of these formulations remained unaltered (Fig. 2), demonstrating their high stability as previously described [27].

We have tested the stability of nanoemulsions containing Poloxamer 407 when exposed to biological medium (see Section 2 for details). Minor variations $(<10 \%)$ in the size of the nanoemulsions were observed after $24 \mathrm{~h}$ of incubation while the respective zeta-

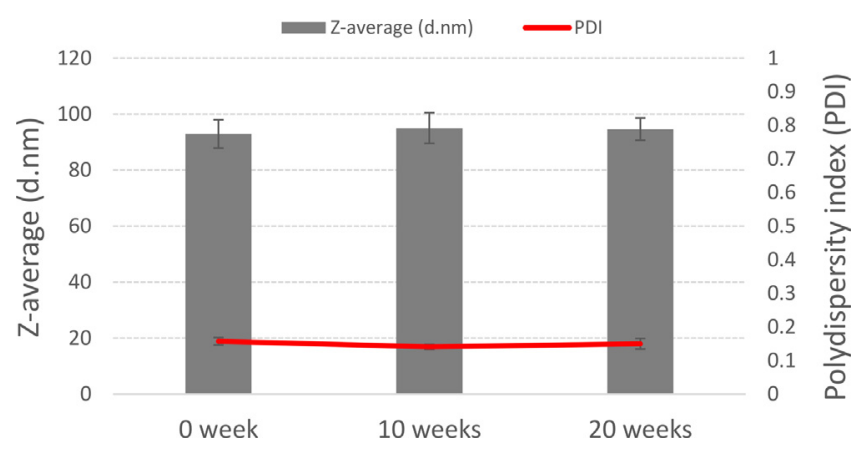

Fig. 2. Time-course of the particle diameter ( $\mathrm{nm}$ ) and polydispersity index values of BSA nanoemulsions containing Poloxamer 407; nanoemulsions were prepared using $99.5 \%$ aqueous solution containing BSA at $10 \mathrm{mg} / \mathrm{mL}$ and Poloxamer 407 at $5 \mathrm{mg} / \mathrm{mL} / 0.5 \%$ vegetable oil. Values are the mean \pm SEM of 3 independent experiments.

potential values remained unaltered. Given the high ionic strength of the biological medium and the high salt and content, these results demonstrated the nanoemulsions' high stability [28].

Poloxamers are known to bind to the surface of the nanospheres through hydrophobic interaction of the PPO chains, whilst the hydrophilic PEG chains extend into the surrounding medium and create a steric barrier to form a protective coating [29-33]. We suggest that the mechanism of nanoemulsion formation, as well as its tunable properties such as size, arise from the chemical nature of both the Poloxamer and the BSA protein, and the subsequent physicochemical interactions between them. Thus, the steric barrier resulting from hydrophilic PEG chains of Poloxamer may prevent the interaction between an approaching nanoparticle and the target cell. PEG molecules can also reduce the adsorption of opsonins and other serum proteins through a mechanism known as the steric repulsion effect [32,34]. PEG molecules will form a dynamic molecular "cloud" over the particle surface, due to the chain flexibility and the electrical neutrality of the PEG backbone $[32,34,35]$. A correlation between surface charge and opsonization has also been demonstrated in vitro, indicating that neutral charged particles have a much lower clearance from circulation than electrically charged particles [36]. In a previous study, we demonstrated that nanoparticles containing $2.5 \mathrm{mg} / \mathrm{mL}$ of PEGylated surfactant are more readily recognized and internalized by macrophages than nanoparticles containing $5 \mathrm{mg} / \mathrm{mL}$ of surfactant [27]. These results showed that the presence of PEGylated surfactant at a concentration of $5 \mathrm{mg} / \mathrm{mL}$ appears to promote PEG chains to sufficiently extend into the aqueous solution to shield the surface of the nanoparticles and improve resistance to macrophage uptake. Therefore, this neutral and hydrophilic surface in PEGylated nanoemulsions can generate stealth particles that are less phagocytized, resulting in a longer half-life in systemic circulation [27].

Molecular dynamics simulation was used to better understand the interactions between Poloxamer 407 and BSA with the oil phase, as experimentally, it is very difficult to clarify the interaction between components. The results obtained clearly illustrate the interactions between the components of the system (Fig. 3A). The hydrophobic part of Poloxamer 407 (blue = polyoxypropylene part) interacts preferably with the oil, decreasing hydrophobic interactions between the oil and the protein, which may be responsible for nanoemulsion size reduction upon surfactant addition.

Upon analyzing the radial distribution of the components (Fig. 3B), an additional tool to clarify the relative positions of the components, we may speculate that the polyoxypropylene component is in close proximity to the oil whilst the polyoxyethylene interacts preferentially with the protein. The overall tri-block surfactant seems to make a matrix with the protein surrounding the 
A.

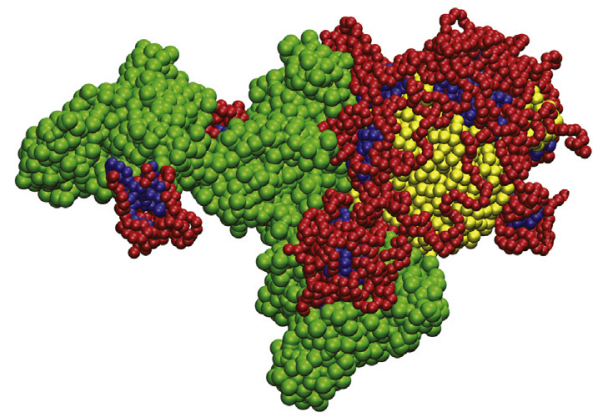

B.

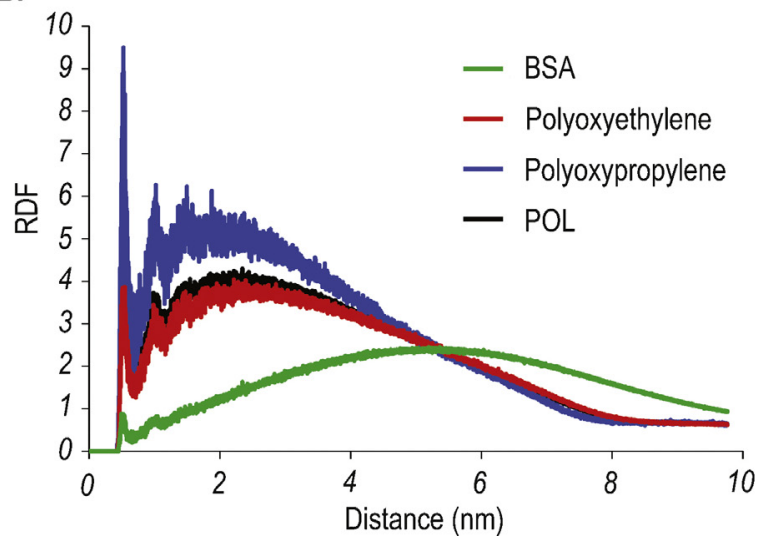

C.
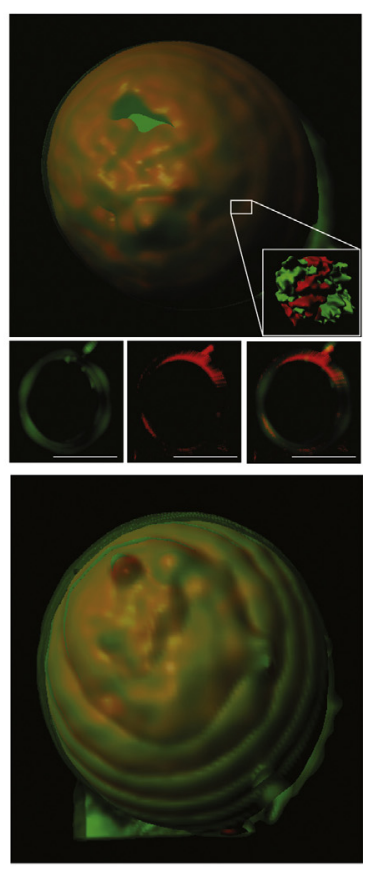

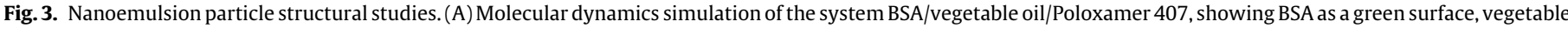

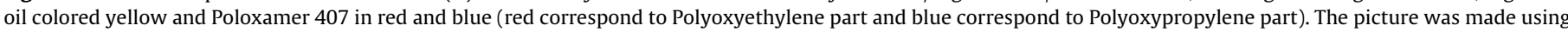

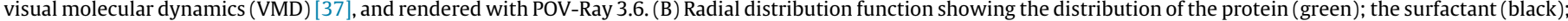

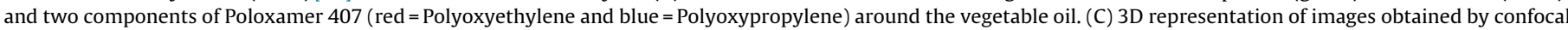

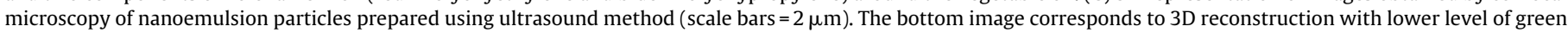
transparency comparatively to top image. (For interpretation of the references to colour in this figure legend, the reader is referred to the web version of this article.)

oil, which is in line with the results obtained by the zeta-potential measurements that indicated that nanoemulsions without Poloxamer 407 exhibit negatively charged particles while the presence of Poloxamer 407 leads to a neutral particle surface.

An emulsion using BSA labeled with FITC and Poloxamer 407 labeled with rhodamine B was prepared using ultrasounds, which also involves high shear forces, so as to obtain larger particles suitable for confocal microscopy. 3D Reconstruction of the images obtained with the confocal microscope confirmed that the nanoemulsion particle shells were composed of protein and PEGylated surfactant (Fig. 3C). The PEGylated surfactant is found preferentially at the oil interface but also on the surface of the protein shell, with both components interacting in order to form the shell of the nanoemulsion particles, as suggested by the zetapotential measurements.

\subsection{Biological characterization of nanoemulsion formulations}

In order to evaluate the cytotoxicity of nanoemulsion formulations containing Poloxamer 407, cell viability was assessed in human skin fibroblasts (BJ5ta cell line) using the MTS assay. Nanoemulsions with surfactant did not induce toxicity at the wide range of concentrations tested, over a period of $72 \mathrm{~h}$ of contact (Table 1). Cell viability was also evaluated at 24 and $48 \mathrm{~h}$ (data not shown). One important potential risk of using nanostructured formulations is the possibility of eliciting high levels of intracellular reactive oxygen species (ROS), causing the deleterious oxidation of biomolecules. To evaluate if the nanoemulsion formulations induce the production of intracellular ROS, the $2^{\prime} 7^{\prime}$-dichlorofluorescein
(DCF) assay was used. In this assay, intracellular ROS oxidate the non-fluorescent $\mathrm{DCFH}_{2}$ to a highly fluorescent compound, DCF, which is then quantified. The intensity of the fluorescent signal detected by this method is proportional to the amount of ROS produced within the cells. Nanoemulsion formulations did not induce oxidative stress in human BJ5ta cells (Table 1).

\subsection{Production and characterization of FA-PEGylated BSA nanoemulsions}

For evaluating FR-mediated cell targeting, nanoemulsions containing imaging and targeting agents were prepared by introducing BSA-FITC and BSA-FA conjugates, respectively. BSA-FITC was introduced into the initial formulation, containing $5 \mathrm{mg} / \mathrm{mL}$ of Poloxamer 407, at a $1: 20$ ratio $(\mathrm{m} / \mathrm{m})$ and BSA-FA at a $1: 100$ ratio $(\mathrm{m} / \mathrm{m})$ relative to the BSA protein. Fluorescence microscopy observations and quantification of FA, using RIDASCREEN ${ }^{\circledR}$ FAST Folic acid test kit, demonstrated that fluorescently labeled BSA and a high FA concentration were present at the nanoemulsion's surface $(633.2 \pm 114.39 \mu \mathrm{g} / \mathrm{L})$. The physicochemical characterization of nanoemulsions containing FA was performed and we observed that the values of size, PDI and zeta-potential are similar to that of non-targeted PEGylated nanoemulsions.

Subsequent studies, including cellular internalization of tagged nanoemulsions, were performed using these PEGylated nanoemulsions containing $5 \mathrm{mg} / \mathrm{mL}$ of Poloxamer 407. Their small size (under $100 \mathrm{~nm}$ ) and stealth characteristic make them ideal nanoparticles for intravenous application. The higher concentration of Poloxamer 407 induce a better stealth, which might reduce the interaction 
A

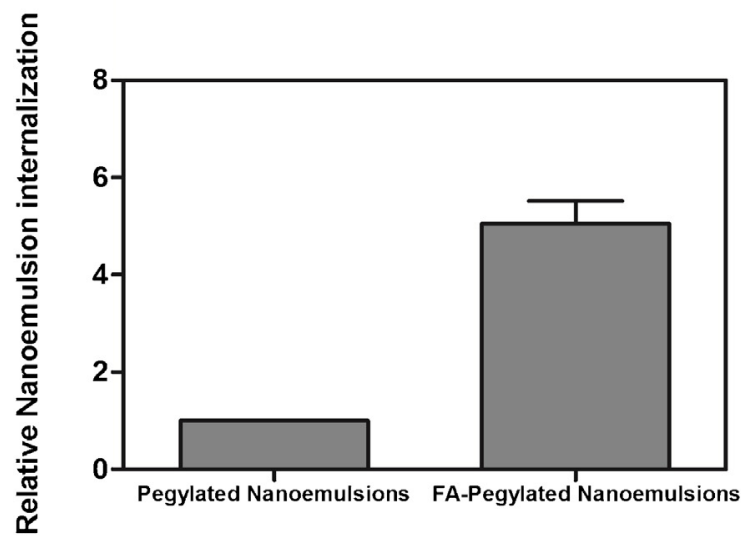

B

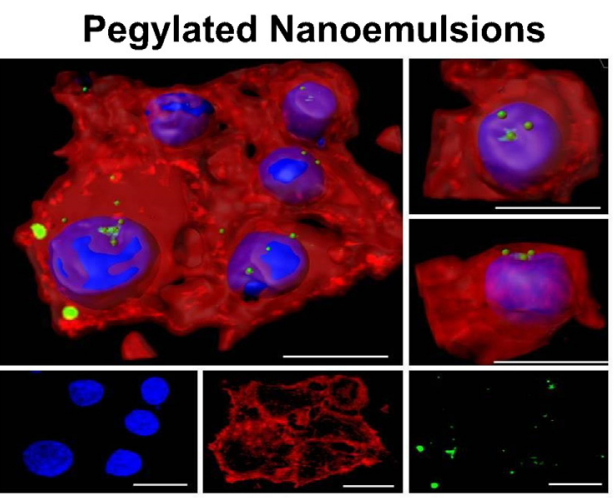

\section{FA-Pegylated Nanoemulsions}

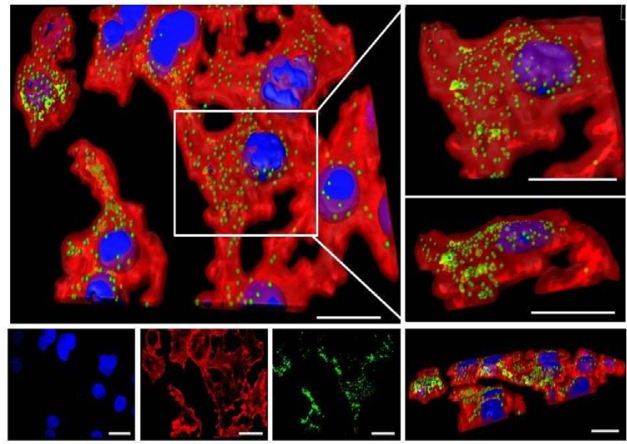

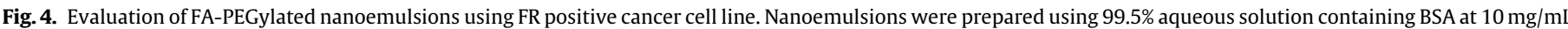

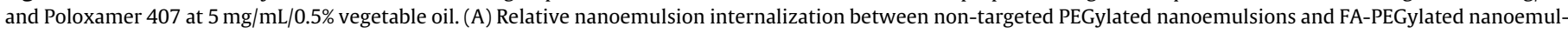

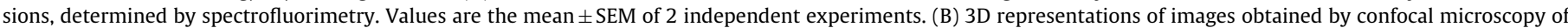

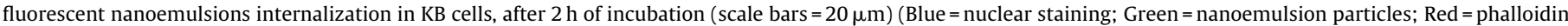
cytoskeleton staining). (For interpretation of the references to colour in this figure legend, the reader is referred to the web version of this article.)

between nanoparticle and the cell, decreasing their unspecific cellular uptake [38,39]. This phenomenon favors specific cell uptake mediated by folate.

Specific cellular internalization of functionalized nanoemulsions was then evaluated in FR positive KB cell line $[40,41]$ FA conjugates typically exhibit high binding affinities for FR $(\mathrm{KD}=1-10 \mathrm{nM})$, which is abundantly overexpressed in many malignant tumors - for example, up to $80 \mathrm{pmol}$ ( $\mathrm{mg}$ membrane protein) in $\mathrm{KB}$ cells. The quantification of internalization by spectrofluorimetry demonstrated that the FA-PEGylated nanoemulsions are internalized by cells more efficiently and to a higher extent ( 5 fold) than non-targeted PEGylated nanoemulsions (Fig. 4A).

$3 \mathrm{D}$ reconstructions of images obtained by confocal microscopy also showed the specific internalization of FA-nanoemulsions with the involvement of the cell membrane (Fig. 4B). Similar specificity in FA-mediated cell uptake of these nanoemulsions was verified in other FR-alpha positive cell lines, MDA-MB 468 [42,43] and Caco-2 $[44,45]$ (data not shown). While for these cancer cell lines no competitive studies were done, in primary activated human macrophages, which are known to express FR-beta, these were performed using an anti-human FR-beta antibody. When the FR-beta was preliminarily blocked with the FR antibody, no significant differences in cell internalization were observed between FA-PEGylated nanoemulsions and non-targeted PEGylated nanoemulsions. However, experiments with the unblocked FR demonstrated a $40 \%$ increased of the internalization for the FA-targeted nanoemulsions. The comparison between FA-targeted nanoemulsions internalization with and without FR blocking also demonstrated differences, with a significant inhibition of internalization observed when the FR was blocked.

These results suggest that FA-PEGylated nanoemulsions interact efficiently with FR at the cellular surface and promote FR-mediated endocytosis.

\subsection{Drug delivery applications}

As this versatile system is intended for drug delivery purposes, we performed the entrapment of different pharmacological drugs, which were successfully incorporated in the nanoemulsions (Table 2).

The general characteristics of the nanoemulsions were not significantly altered by drug loading, although the entrapment efficiency was different according to the drug included. Entrapment efficiency of lipophilic drugs may be considered to be $100 \%$ as the oil phase is totally incorporated in the nanoemulsions. The percentage of entrapped drug was smaller in the case of hydrophilic drugs. Additionally, we performed a study of drug release for nanoemulsions loaded with methotrexate. 20 days after nanoemulsion preparation, a phase separation was performed to separate the free drug from the encapsulated fraction using PD-10 desalting columns (GE Healthcare). The quantification of methotrexate in the aqueous phase separated demonstrated that approximately $43 \%$ of the drug had been released. All these results of the entrapment of drugs and the structural studies of these nanoemulsions suggest that they can efficiently incorporate hydrophobic compounds. 
Table 2

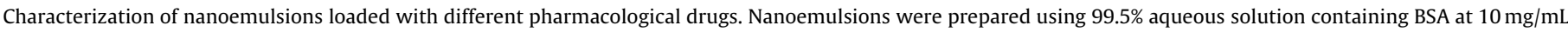
and Poloxamer 407 at $5 \mathrm{mg} / \mathrm{mL} / 0.5 \%$ vegetable oil. (n.d. = not determined).

\begin{tabular}{|c|c|c|c|c|}
\hline & Compound structure & Compound solubility & $Z$-average [d.nm] (PDI) & Entrapment efficiency (\%) \\
\hline Nanoemulsions with 5-Fluorouracil & & Hydrophilic & n.d. & $26.0 \pm 3.5$ \\
\hline Nanoemulsions with Doxorrubicin & $\mathrm{NH}_{2}$ & Hydrophilic & $\begin{array}{l}84.57 \pm 0.73 \\
(0.130 \pm 0.004)\end{array}$ & $47.3 \pm 6.4$ \\
\hline Nanoemulsions with Methotrexate & & Hydrophilic & $\begin{array}{l}84.51 \pm 0.36 \\
(0.166 \pm 0.002)\end{array}$ & $25.0 \pm 2.6$ \\
\hline Nanoemulsions with Taxol & & Lipophilic & $\begin{array}{l}93.85 \pm 0.71 \\
(0.136 \pm 0.017)\end{array}$ & n.d. ${ }^{a}$ \\
\hline Nanoemulsions with CORM-2 & $\mathrm{Cl}$ & Lipophilic & $\begin{array}{l}89.86 \pm 4.24 \\
(0.143 \pm 0.016)\end{array}$ & n.d. ${ }^{a}$ \\
\hline
\end{tabular}

a Entrapment efficiency of lipophilic drugs may be considered to be $100 \%$ as the oil phase is totally incorporated in the nanoemulsions.

These novel FA-PEGylated BSA nanoemulsions thus arise as promising vehicles for selective delivery of drugs to a target cell population that overexpresses FR.

\section{Conclusions}

In conclusion, we have developed a high pressure homogenization procedure that enables the formation of size controlled, stable and functionalized BSA nanoemulsions. The amount of protein and the hydrophobic phase volume were demonstrated to be crucial parameters in the nanoemulsion formation process, as previously described for ultrasound method [10]. By combining this novel production method with the introduction of Poloxamer 407 , protein-based nanoemulsions with controllable size were developed. The inclusion of FA in the formulation allowed the functionalization of such vectors for FA-mediated active targeting of FR positive cells. Their small size, high stability over time and absence of cytotoxicity, together with their specific targeting capacity in cells expressing FR, are ideal characteristics to support their application in drug delivery into diseased tissues. The procedure here described can be used to produce virtually any type of function- alized protein-based nanoemulsions increasing their scope as a vehicle for targeted drug delivery purposes.

\section{Acknowledgements}

Ana Loureiro (SFRH/BD/81479/2011) and Eugénia Nogueira (SFRH/BD/81269/2011) hold scholarships from Fundação para a Ciência e a Tecnologia (FCT). Gonçalo J. L. Bernardes is a Royal Society University Research Fellow at the Department of Chemistry, University of Cambridge and an Investigador FCT at the Instituto de Medicina Molecular, Faculdade de Medicina da Universidade de Lisboa. We thank Patrícia Nogueira, Jaime Freitas, Alexandra Moreira and Alexandre M. Carmo from Instituto de Biologia Molecular e Celular (IBMC) by the cellular experiments using primary activated human macrophages. We also thank Bruno Fernandes for technical assistance in experiments of nanoparticle stability in biological medium. This work has received funding from the European Union Seventh Framework Programme (FP7/2007-2013) under grant agreement NMP4-LA-2009-228827 NANOFOL. This work was supported by FEDER through POFC - COMPETE and by Portuguese funds from FCT through the project PEst-OE/BIA/UI4050/2014. The authors also thank the FCT Strategic Project of UID/BIO/04469/2013 unit. 


\section{References}

[1] K. Cho, X. Wang, S. Nie, Z. Chen, D.M. Shin, Therapeutic nanoparticles for drug delivery in cancer, Clin. Cancer Res. 14 (2008) 1310-1316.

[2] K. Langer, S. Balthasar, V. Vogel, N. Dinauer, H. von Briesen, D. Schubert, Optimization of the preparation process for human serum albumin (HSA) nanoparticles, Int. J. Pharm. 257 (2003) 169-180.

[3] S. Suri, H. Fenniri, B. Singh, Nanotechnology-based drug delivery systems, J. Occup. Med. Toxicol. 2 (2007) 16.

[4] A.O. Elzoghby, W.M. Samy, N.A. Elgindy, Albumin-based nanoparticles as potential controlled release drug delivery systems, J. Controlled Release 157 (2012) 168-182.

[5] D. Peer, J.M. Karp, S. Hong, O.C. Farokhzad, R. Margalit, R. Langer, Nanocarriers as an emerging platform for cancer therapy, Nature Nanotechnol. 2 (2007) $751-760$.

[6] U. Shimanovich, G.J.L. Bernardes, T.P.J. Knowles, A. Cavaco-Paulo, Protein micro- and nano-capsules for biomedical applications, Chem. Soc. Rev. 43 (2014) 1361-1371.

[7] N. Anton, J.-P. Benoit, P. Saulnier, Design and production of nanoparticles formulated from nano-emulsion templates-a review, J. Controlled Release 128 (2008) 185-199.

[8] G.V. Patil, Biopolymer albumin for diagnosis and in drug delivery, Drug Dev. Res. 58 (2003) 219-247.

[9] K.S. Suslick, M.W. Grinstaff, Protein microencapsulation of nonaqueous liquids, J. Am. Chem. Soc. 112 (1990) 7807-7809.

[10] R. Silva, H. Ferreira, N.G. Azoia, U. Shimanovich, G. Freddi, A. Gedanken, A. Cavaco-Paulo, Insights on the mechanism of formation of protein microspheres in a biphasic system, Mol. Pharm. 9 (2012) 3079-3088

[11] D.A. Armbruster, T. Pry, Limit of blank, limit of detection and limit of quantitation, Clin. Biochem. Rev. 29 (2008) S49-S52.

[12] S. Pronk, S. Páll, R. Schulz, P. Larsson, P. Bjelkmar, R. Apostolov, M.R. Shirts, J.C. Smith, P.M. Kasson, D. van der Spoel, B. Hess, E. Lindahl, GROMACS 4. 5: a high-throughput and highly parallel open source molecular simulation toolkit, Bioinformatics 29 (2013) 845-854.

[13] H. Lee, A.H. de Vries, S.-J. Marrink, R.W. Pastor, A coarse-grained model for polyethylene oxide and polyethylene glycol: conformation and hydrodynamics, J. Phys. Chem. B 113 (2009) 13186-13194.

[14] S.J. Marrink, H.J. Risselada, S. Yefimov, D.P. Tieleman, A.H. de Vries, The MARTINI force field: coarse grained model for biomolecular simulations, J. Phys. Chem. B 111 (2007) 7812-7824.

[15] L. Monticelli, S.K. Kandasamy, X. Periole, R.G. Larson, D.P. Tieleman, S.-J. Marrink, The MARTINI coarse-grained force field: extension to proteins, J. Chem. Theory Comput. 4 (2008) 819-834.

[16] B. Hess, H. Bekker, H.J.C. Berendsen, J.G.E.M. Fraaije, LINCS: a linear constraint solver for molecular simulations, J. Comput. Chem. 18 (1997) 1463-1472.

[17] H.J.C. Berendsen, J.P.M. Postma, W.F. van Gunsteren, A. DiNola, J.R. Haak, Molecular dynamics with coupling to an external bath, J. Chem. Phys. 81 (1984) 3684-3690.

[18] B. Neises, W. Steglich, Simple method for the esterification of carboxylic acids, Angew. Chem. Int. Ed. Engl. 17 (1978) 522-524.

[19] L. Jiang, X. Zeng, Z. Wang, Q. Chen, Cell line cross-contamination: KB is not an oral squamous cell carcinoma cell line, Eur. J. Oral Sci. 117 (2009) 90-91.

[20] S. Schultz, G. Wagner, K. Urban, J. Ulrich, High-pressure homogenization as a process for emulsion formation, Chem. Eng. Technol. 27 (2004) 361-368.

[21] A. Lamprecht, N. Ubrich, M. Hombreiro Pérez, C.M. Lehr, M. Hoffman, P. Maincent, Biodegradable monodispersed nanoparticles prepared by pressure homogenization-emulsification, Int. J. Pharm. 184 (1999) 97-105.

[22] W.-k. Lee, J.-y. Park, E.H. Yang, H. Suh, S.H. Kim, D.S. Chung, K. Choi, C.W. Yang, J.-s. Park, Investigation of the factors influencing the release rates of cyclosporin A-loaded micro- and nanoparticles prepared by high-pressure homogenizer, J. Controlled Release 84 (2002) 115-123.

[23] R. Ambrus, P. Kocbek, J. Kristl, R. Šibanc, R. Rajkó, P. Szabó-Révész, Investigation of preparation parameters to improve the dissolution of poorly water-soluble meloxicam, Int. J. Pharm. 381 (2009) 153-159.

[24] A. Lamprecht, N. Ubrich, M. Hombreiro Pérez, C.M. Lehr, M. Hoffman, P. Maincent, Influences of process parameters on nanoparticle preparation performed by a double emulsion pressure homogenization technique, Int. J. Pharm. 196 (2000) 177-182.

[25] C. Pinto Reis, R.J. Neufeld, A.J. Ribeiro, F. Veiga, Nanoencapsulation I. Methods for preparation of drug-loaded polymeric nanoparticles, Nanomedicine 2 (2006) 8-21.
[26] I. Gonçalves, M. Martins, A. Loureiro, A. Gomes, A. Cavaco-Paulo, C. Silva, Sonochemical and hydrodynamic cavitation reactors for laccase/hydrogen peroxide cotton bleaching, Ultrason. Sonochem. 21 (2014) 774-781.

[27] E. Nogueira, A. Loureiro, P. Nogueira, J. Freitas, C.R. Almeida, J. Harmark, H. Hebert, A. Moreira, A.M. Carmo, A. Preto, A.C. Gomes, A. Cavaco-Paulo, Liposome and protein based stealth nanoparticles, Faraday Discuss. 166 (2013) 417-429.

[28] S.S. Rohiwal, A.P. Tiwari, G. Verma, S.H. Pawar, Preparation and evaluation of bovine serum albumin nanoparticles for ex vivo colloidal stability in biological media, Colloids Surf. A Physicochem. Eng. Aspects 480 (2015) 28-37.

[29] S.M. Moghimi, I.S. Muir, L. Illum, S.S. Davis, V. Kolb-Bachofen, Coating particles with a block co-polymer (poloxamine-908) suppresses opsonization but permits the activity of dysopsonins in the serum, Biochim. Biophys. Acta 1179 (1993) 157-165

[30] S.M. Moghimi, A.C. Hunter, J.C. Murray, Long-circulating and target-specific nanoparticles: theory to practice, Pharmacol. Rev. 53 (2001) 283-318.

[31] S.E. Dunn, A.G.A. Coombes, M.C. Garnett, S.S. Davis, M.C. Davies, L. Illum, In vitro cell interaction and in vivo biodistribution of poly(lactide-co-glycolide) nanospheres surface modified by poloxamer and poloxamine copolymers, J. Controlled Release 44 (1997) 65-76.

[32] R. Gref, A. Domb, P. Quellec, T. Blunk, R.H. Müller, J.M. Verbavatz, R. Langer, The controlled intravenous delivery of drugs using PEG-coated sterically stabilized nanospheres, Adv. Drug Delivery Rev. 16 (1995) 215-233.

[33] R. Fernández-Urrusuno, E. Fattal, D. Porquet, J. Féger, P. Couvreur, Influence of surface properties on the inflammatory response to polymeric nanoparticles, Pharm. Res. 12 (1995) 1385-1387.

[34] A.S. Zahr, C.A. Davis, M.V. Pishko, Macrophage uptake of core-shell nanoparticles surface modified with poly(ethylene glycol), Langmuir 22 (2006) 8178-8185

[35] V.C.F. Mosqueira, P. Legrand, R. Gref, B. Heurtault, M. Appel, G. Barratt, Interactions between a macrophage cell line (J774A1) and surface-modified poly(D,L-lactide) nanocapsules bearing poly(ethylene glycol), J. Drug Target. 7 (1999) 65-78

[36] D.E. Owens, N.A. Peppas, Opsonization, biodistribution, and pharmacokinetics of polymeric nanoparticles, Int. J. Pharm. 307 (2006) 93-102.

[37] W. Humphrey, A. Dalke, K. Schulten, VMD: visual molecular dynamics, J. Mol. Graphics 14 (1996) 33-38

[38] J.M. Morachis, E.A. Mahmoud, A. Almutairi, Physical and chemical strategies for therapeutic delivery by using polymeric nanoparticles, Pharmacol. Rev. 64 (2012) 505-519.

[39] S. Salmaso, P. Caliceti, Stealth properties to improve therapeutic efficacy of drug nanocarriers, J. Drug Delivery 2013 (2013) 19.

[40] J.A. Reddy, E. Westrick, H.K.R. Santhapuram, S.J. Howard, M.L. Miller, M. Vetzel, I. Vlahov, R.V. Chari, V.S. Goldmacher, C.P. Leamon, Folate receptor-specific antitumor activity of EC131, a folate-maytansinoid conjugate, Cancer Res. 67 (2007) 6376-6382.

[41] Q. Tang, Y. An, D. Liu, P. Liu, D. Zhang, Folate/NIR 797-conjugated albumin magnetic nanospheres: synthesis, characterisation, and in vitro and in vivo targeting evaluation, PLoS One 9 (2014) e106483.

[42] P. Panwar, V. Shrivastava, V. Tandon, P. Mishra, K. Chuttani, R.K. Sharma, R. Chandra, A.K. Mishra, 99mTc-Tetraethylenepentamine-folate a new 99mTc based folate derivative for the detection of folate receptor positive tumors: synthesis and biological evaluation, Cancer Biol. Ther. 3 (2004) 995-1001.

[43] K.R. Colacino, C.B. Arena, S. Dong, M. Roman, R.V. Davalos, Y.W. Lee, Folate conjugated cellulose nanocrystals potentiate irreversible electroporation-induced cytotoxicity for the selective treatment of cancer cells, Technol. Cancer Res. Treat. (2014).

[44] S.D. Weitman, R.H. Lark, L.R. Coney, D.W. Fort, V. Frasca, V.R. Zurawski, B.A. Kamen, Distribution of the folate receptor GP38 in normal and malignant cell lines and tissues, Cancer Res. 52 (1992) 3396-3401.

[45] E. Roger, S. Kalscheuer, A. Kirtane, B.R. Guru, A.E. Grill, J. Whittum-Hudson, J. Panyam, Folic acid-functionalized nanoparticles for enhanced oral drug delivery, Mol. Pharm. 9 (2012) 2103-2110. 